\title{
MUJERES PIONERAS: LA CATEDRÁTICA DE INSTITUTO ROSARIO FUENTES
}

\author{
Pioneering women: the secondary school professor \\ Rosario Fuentes
}

\author{
Jorge Fernàndez Gonzàlez ${ }^{\alpha}$
}

Fecha de recepción: 14/05/2020 • Fecha de aceptación: 18/09/2020

Resumen. Si la educación superior estuvo vetada y limitada a las mujeres hasta el siglo XX, su acceso a la docencia en estos espacios y a sus cátedras fue aún más difícil y complejo. En el presente trabajo se describe el caso paradigmático de Rosario Fuentes, número uno en sus oposiciones a cátedra de francés y primera catedrática del Instituto Zorrilla de Valladolid. Además, tuvo una relevante trayectoria como traductora, con su aportación en textos relacionados con el ámbito de la educación, la filosofía o la psicología. En este estudio se destaca su faceta como investigadora relacionada con la Junta para la Ampliación de Estudios y como creadora de libros de texto. También participó en organizaciones de profesorado de lenguas vivas y dio clases en diferentes Escuelas Normales y de Magisterio. Una trayectoria que se vio en parte ensombrecida por un proceso de depuración al que sometió el franquismo al profesorado, que fue en ocasiones más arbitrario con las mujeres al no tener en cuenta sus propias ideas y acciones, sino las de sus parejas o familiares. En este artículo se abordan diversos aspectos de los mencionados a partir de documentación e imágenes inéditas disponibles en diferentes archivos como los de la administración y de la familia, así como de trabajos previos que abordaron la cuestión del profesorado femenino en la Segunda Enseñanza.

Palabras clave: catedráticas de instituto; Educación Secundaria; depuración del profesorado; JAE; mujeres pioneras.

Abstract. If higher education was already restricted and off-limits to women until the 20th century, their access to teaching and obtaining academic positions

\footnotetext{
${ }^{\alpha}$ Departamento de Didáctica de las Ciencias Experimentales y Sociales. Facultad de Magisterio, Universitat de València. Av. dels Tarongers, 4, 46022 València, España. jfern112@xtec.cat (D) https:// orcid.org/0000-0001-8738-8746
} 
at these levels was even more difficult and complex. The aim of this paper is to describe a paradigmatic case of this problem: the life of Rosario Fuentes, who achieved the highest score in a public exam to become French professor and who became the first secondary school professor at the Zorrilla high school in Valladolid. Fuentes alsohad a relevant career as a translator, with contributions to texts on education, philosophy and psychology. This study highlights her role as a researcher associated with the Junta para la Ampliación de Estudios (Board for Advanced Studies) and as a writer of French textbooks. She also took part in the organization of language teachers as well as teaching in different Teacher Training Schools. Her career suffered as a result of the purging process which Franco's dictatorship carried out on teachers, a process that was especially arbitrary against women due to the fact that their own actions and thoughts were often considered less relevant than those of their partners or relatives.. This paper, which examines many of these aspects of her life, relies on documentation and unpublished images from different archives such as those of the administration and the family, as well as previous works that analyse the issue of women teachers in Secondary Education.

Keywords: female secondary teachers; Secondary Education; teachers' purge; Board for Advanced Studies-JAE; pioneering women.

Es importante conocer las trayectorias detrás de los nombres propios de una generación de mujeres que se abrió camino en la educación para visibilizar su papel. Uno de estos nombres es el de Rosario Fuentes Pérez (1898-1970). Nació en la calle de Claudio Coello número 103 de Madrid en octubre de 1898, casualmente el año de la independencia de Cuba y Filipinas. En esa guerra y en otras como la de África participó su padre, Julio Fuentes y Forner, militar alicantino que llegó a ser comandante general de Artillería en Cuba y gobernador civil de Barcelona, casado con la valenciana María Pérez y Almunia.

En el caso de Rosario, consiguió estudiar más de lo que era habitual en la época para las mujeres. Estudió en la Escuela Normal de Toledo y obtuvo, en noviembre de 1917, el título de Maestra de Primera Enseñanza. Posteriormente, realizó estudios de bachillerato y universitarios e incluso comenzó estudios de doctorado. Fue una de las primeras catedráticas de instituto y destacó en diferentes ámbitos como la traducción, la elaboración de libros de texto o la investigación, ámbitos que en la época estaban prácticamente copados por hombres.

El presente estudio centra su atención en Rosario Fuente Pérez y la importancia de su figura para entender la historia de la incorporación de 
las mujeres en el sistema educativo y al cuerpo de catedráticos. Así, también se repasan las pensiones solicitadas y disfrutadas a la Junta para la Ampliación de Estudios para realizar investigaciones sobre educación y el francés en el extranjero. Además, se establece una relación de obras traducidas y escritas por ella, así como su impacto y relevancia en el ámbito educativo. Por último, se centra la mirada en su proceso de depuración a partir de la documentación existente sobre todo el proceso.

\section{LAS MUJERES EN LA EDUCACIÓN SUPERIOR: DE LA LIMITACIÓN LEGAL A SU LENTA INCORPORACIÓN}

La primera legislación educativa que intentó abordar de manera integral el analfabetismo y la cuestión educativa en España fue la Ley de Instrucción Pública de 1857, conocida como Ley Moyano. Esta ley hacía obligatoria la instrucción de los niños y las niñas en los niveles básicos de enseñanza: entre los seis y los nueve años, aunque no en las mismas condiciones. ${ }^{1}$ A nivel social, existía un debate sobre la idoneidad de que las niñas tuvieran la posibilidad de obtener los mismos conocimientos que los niños.

En el caso de la educación no obligatoria, los debates no se centraban tanto en esa pertinencia o no, sino en la propia capacidad intelectual de las mujeres para poder estudiar en determinados niveles superiores como los estudios de bachillerato o los universitarios. Cabe recordar que, si los estudios universitarios eran inaccesibles para la inmensa mayoría de la población por su estructura social, aún lo era más para el caso de las mujeres:

Tanto el instituto como la universidad eran instituciones escolares pensadas exclusivamente para la formación masculina, santuarios del saber que, en correspondencia con el poder, estaban reservados para las clases medias y altas de la mitad de la población, la destinada a ocupar los puestos rectores de la sociedad y dinamizar el desarrollo económico de la nación. ${ }^{2}$

\footnotetext{
1 Diego Sevilla, «La ley Moyano y el desarrollo de la educación en España», Ethos educativo, 40 (2007): 117.

2 Carmen Benso, «Exclusión, discriminación y resistencias: el acceso de la mujer al sistema educativo (1833-1930)» en Xénero e educación social, coord. Elisa Jato y Lucía Iglesias (Santiago de Compostela, Edicións Laiovento, 2003), 65.
} 
Ni siquiera se concebía socialmente que las mujeres pudieran estudiar y trabajar en profesiones de carácter intelectual, por lo que no existía legislación explícita al respecto. Fue este un vacío legal que aprovecharon algunas precursoras para matricularse en carreras universitarias, como María Elena Maseras, quien en 1872 se convirtió en la primera española matriculada en la Facultad de Medicina de la Universidad de Barcelona. No obstante, los requisitos que se les demandaba y los trámites que debían realizar eran muy diferentes a los de sus compañeros. ${ }^{3}$ Además, la presencia de alumnas en clase no estaba bien visto, por lo que o bien no acudían o bien eran objeto de vejaciones y agresiones. ${ }^{4}$ Más adelante, en 1882, se introdujo un cambio legislativo que, esta vez sí, prohibió explícitamente que las mujeres pudieran matricularse en niveles superiores de enseñanza e inhabilitó sus títulos para ejercer en el ámbito público. Entre 1888 y 1910 se permitió su estudio únicamente en la modalidad de enseñanza privada; si querían asistir a las clases como alumnas oficiales podrían hacerlo previa autorización expresa del Ministerio del que dependían los asuntos de Instrucción Pública. ${ }^{5}$ En 1910 se permitió el acceso de la mujer a estudios de enseñanza superior en igualdad de condiciones, sin restricciones legales y con reconocimiento de los títulos para ejercer en profesiones públicas, aunque fue un proceso largo si atendemos al porcentaje de mujeres matriculadas en bachillerato. ${ }^{6}$

Si resultó tardía la incorporación como alumnas en los institutos de segunda enseñanza, lo fue más aún su incorporación como docentes en este nivel educativo, y todavía más su acceso a las cátedras de instituto. La primera mujer en desarrollar tareas docentes en un instituto fue Julia Gomis Llopis en el Instituto de València, pero lo hizo como ayudante gratuito y no fue hasta 1918 que se convirtió en la primera auxiliar numeraria de Dibujo, puesto para el que no hacía falta tener estudios

\footnotetext{
3 Consuelo Flecha, Las primeras universitarias en España (1872-1910) (Madrid: Narcea, 1996).

4 Rosario de Acuña relató un suceso de vejaciones en prensa (Véase «La jarca de la Universidad», El Progreso Barcelona, 22 de novembre de 1911) y tuvo que exiliarse en Portugal.
}

5 María Poveda, Mujeres y segunda enseñanza en Madrid (1931-1939). El personal docente femenino en los institutos de bachillerato"(Tesis doctoral, Universidad Complutense de Madrid, 2014), 65.

6 Antonio Viñao, «Del bachillerato de élite a la educación secundaria para todos» en Historia de la Enseñanza Media en Aragón, coord. Guillermo Vicente (Zaragoza: Institución Fernando el Católico, 2011), 455. 
universitarios. A partir de ese año se incorporaron diferentes profesoras, ya con este tipo estudios. ${ }^{7}$ En lo que respecta al cuerpo de catedráticos, fue en 1923 cuando la primera mujer, María Luisa García-Dorado Seirullo, ganó y ocupó su cátedra de Latín en el Instituto General y Técnico de Castellón. A partir de la década de los años veinte, en parte como consecuencia del incremento de alumnado de bachillerato y la creación de nuevos institutos secundarios, resultó paulatina la incorporación de las mujeres como catedráticas.

Rosario Fuentes, después de obtener el título de Maestra de Primera Enseñanza en la Escuela Normal de Toledo en 1917, finalizó sus estudios de bachillerato en el Instituto de San Isidro de Madrid y estudió la Licenciatura en Filosofía y Letras, sección de Historia, en la Universidad Central de Madrid, donde se tituló a la edad de 27 años. También aprobó diferentes asignaturas del Doctorado de la sección de Ciencias Históricas: Arqueología árabe, Historia de América, Sociología, Latín de ampliación y Bibliografía. ${ }^{8}$ Aunque no llegó a finalizar estos estudios, sí que inició el proceso de elaboración de una tesis doctoral. Esta tesis, dirigida por el historiador Claudio Sánchez Albornoz, trataba sobre la historia de España en el siglo XIV utilizando como fuente principal el Libro de los Estados del Infante D. Juan Manuel. En relación con este mismo libro, colaboró también en la elaboración de un vocabulario del Infante bajo la dirección de Ramón Menéndez Pidal. ${ }^{9}$

En 1928 se convocaron unas oposiciones para cátedras de francés con trece plazas vacantes. Rosario no solo consiguió una de esas plazas, sino que sacó la mejor puntuación y ocupó el primer lugar entre 75 aspirantes. Esta convocatoria supuso un gran hito en la historia de las mujeres en el acceso a las cátedras de institutos, pues hubo una gran presencia femenina entre las aprobadas, muchas de ellas en puestos altos: Josefina Ribelles (tercera, destinada a Manresa), Adela María Trepat Massó (cuarta, a Reus), María Dolores de Palacio y de Azara (sexta, a

\footnotetext{
7 Natividad Araque, «Las primeras mujeres catedráticas de institutos de enseñanza secundaria en España durante la dictadura de Primo de Rivera y su relación con la JAE», en Aulas modernas, ed. Leoncio López-Ocón (Madrid: Universidad Carlos III, 2014), 182.

8 Rosario Fuentes, «Hoja de servicios», 25 de febrero de 1932, Expediente JAE/57-421, Archivo de la Junta para la Ampliación de Estudios (en adelante, JAE).

9 Rosario Fuentes, 11 de agosto de 1930, expediente JAE/57-421, Archivo de la JAE.
} 
Osuna) y Concepción Francés Piña (undécima, a Maó). De hecho, tuvo bastante eco en la prensa de la época, que hablaba de «feminismo triunfante ${ }^{10}$ o evidenciaba la existencia de una "generación de muchachas cultísimas, laboriosas que, sin perder su encantadora feminidad y sus gracias [...] aspiran a grados de cultura que jamás se pensó pudieran caer fuera de las actividades masculinas». ${ }^{11}$

Tras las oposiciones, Rosario ocupó su plaza en Vigo, pero a los pocos días pidió una excedencia. ${ }^{12}$ Durante ese curso, acudió como ayudante gratuito de Francés a las aulas del Instituto Cardenal Cisneros de Madrid, donde creció y vivía su familia. Se reincorporó al servicio en diciembre de 1929 en el Instituto Zorrilla de Valladolid ${ }^{13}$ y se convirtió así en la primera mujer catedrática del centro. Es, por tanto, una figura clave en la historia viva del instituto y para entender papel de la mujer en la historia de la enseñanza secundaria en Valladolid y en España. ${ }^{14}$ Compaginó su tarea docente en el centro con su trabajo como profesora titular de Francés en el Instituto de Idiomas de la Universidad de Valladolid, al que accedió en virtud de un concurso-oposición en 1931.

En los años treinta, en consonancia con su política de expansión escolar, las autoridades republicanas decidieron crear nuevos institutos. Así, en el caso de Madrid, la creación de nuevos centros implicó la demanda de más profesorado. Gracias a ello, Rosario Fuentes, tras haber optado sin éxito a cátedras de la capital en diferentes ocasiones, ${ }^{15}$ pudo

10 El Progreso, 13 de junio de 1928, p. 2, «Cinco mujeres, catedráticos de instituto». Hay un error del diario, que dice que irá al Instituto de La Laguna cuando debería decir «Instituto de Vigo».

$11 A B C, 13$ de junio de 1928, pp. 4-6, «Profesoras de instituto».

12 «Real orden concediendo a doña Rosario Fuentes Pérez la excedencia voluntaria en el cargo de Profesora de Lengua francesa del Instituto nacional de segunda enseñanza de Vigo», Gaceta de Madrid (en adelante, GM) 279, 5 de octubre de 1928.

13 «Real Orden nombrando en propiedad a doña Rosario Fuentes Pérez para la Cátedra de Francés del Instituto nacional de Segunda enseñanza de Valladolid», GM 362, 28 de diciembre de 1929.

14 De hecho, su persona y su figura han sido objeto de diferentes estudios de investigación, como la realizada por la catedrática de Geografía e Historia jubilada de dicho instituto (Véase María Antonia Salvador, «La depuración del profesorado femenino en la guerra civil: el caso de Doña Rosario Fuentes del Instituto Zorrilla de Valladolid», CEE Participación Educativa, 15 (2010)). También se utilizó su imagen para ilustrar el cartel y el programa de las II Jornadas de Patrimonio Educativo celebradas en noviembre de 2018 por la Asociación de Amigos del Instituto Zorrilla, el propio centro educativo y la Fundación Municipal de Cultura del Ayuntamiento de Valladolid.

15 En 1930 se presentó a unas oposiciones para cubrir la cátedra de Francés del Instituto Cervantes (Madrid) y del Maragall (Barcelona) (Véase «Subsecretaría.- Anunciando haber sido admitidos y 
obtener destino en el nuevo Instituto Antonio de Nebrija, donde sería la única mujer encargada de una materia con total responsabilidad. ${ }^{16}$ Allí estuvo trabajando hasta que, en diciembre de 1936, con motivo de la Guerra Civil, fue agregada al Instituto de Badalona (Barcelona) y, posteriormente, en marzo de 1937, al Instituto Maragall de Barcelona. ${ }^{17}$

Una vez acabada la guerra, volvió a su destino en el Zorrilla, donde ocupó su cátedra durante más de veinte años, pero arrastró gran parte de este tiempo una sanción resultado de un proceso de depuración que le impedía ocupar cargos directivos o de responsabilidad. A su vez, compaginó su trabajo en este centro con sus clases en otros lugares: la Escuela de Peritos Industriales y las Escuelas de Magisterio. En el primer caso, trabajó enseñando francés a futuros ingenieros tras aprobar en oposición libre en 1955.18 De hecho, unos años más tarde, en 1958, formaría parte, por turno de rotación, del tribunal de oposiciones. ${ }^{19}$ En el caso de su actividad en la formación inicial del magisterio, fue nombrada en 1957 después de una oposición. ${ }^{20}$

Rosario mantuvo la actividad docente en estos tres ámbitos hasta 1961, ${ }^{21}$ cuando dejó su plaza en el instituto vallisoletano y volvió a sus

excluidos los aspirantes que se indican a las oposiciones a las plazas de Profesor de Lengua francesa, vacante en los Institutos nacionales de Segunda enseñanza de Alcoy, y femeninos de Madrid y Barcelona, agregadas a las de Ávila, Lugo, Calatayud, Zafra y Tortosa», GM 130, 10 de mayo de 1930). Más adelante, en 1934, fue propuesta por el Consejo de Cultura en concurso de méritos para la cátedra vacante en el Instituto Calderón de la Barca (Madrid), para la que se nombró finalmente a Tarsicio Seco Marcos, valorándole principalmente su «antigüedad mucho mayor» que la de Rosario (Véase «Orden nombrando a D. Tarsicio Seco Marcos, Catedrático numerario de Lengua francesa del Instituto Nacional de Segunda enseñanza Calderón de la Barca de Madrid», GM 306, 2 de noviembre de 1935).

16 María Poveda, Mujeres y segunda enseñanza en Madrid, 477.

17 [Declaración jurada para la labor depuradora], 19 de febrero de 1939, Signatura 32-16752-00020, Archivo General de la Administración (en adelante, AGA).

18 «Orden por la que se nombra, en virtud de oposición libre, Profesores especiales de Francés de Escuelas de Peritos Industriales», Boletín Oficial del Estado (en adelante, BOE) 330, 26 de noviembre de 1955.

19 «Profesores de Francés de Escuelas Técnicas de Peritos Industriales.- Orden de 18 de enero de 1958 por la que se nombra el Tribunal que ha de juzgar los ejercicios de la oposición a plazas de la especialidad que se señala», BOE 30, 4 de febrero de 1958.

20 «Orden de 16 de julio de 1957 por la que se nombran en virtud de oposición Profesores especiales de Francés de Escuelas del Magisterio«, BOE 218, 27 de agosto de 1957.

21 No tuvo que elegir entre los diferentes puestos ya que no coincidían en horarios. Bastaba con pedir un informe al Ministerio que declarara la compatibilidad entre las actividades realizadas como 
orígenes, empezando a trabajar en el madrileño Instituto de San Isidro, donde cursó sus estudios. ${ }^{22}$ Allí compaginó su trabajo con las clases de Francés en las dos Escuelas de Magisterio de Madrid: la Escuela Pablo Montesinos (masculina) y la Escuela María Díaz Jiménez (femenina) desde 1964. En septiembre de 1967 pidió la excedencia por no poder compaginarlo con sus horarios en el instituto ${ }^{23}$, donde daría clases un año más hasta jubilarse en octubre de 1968.

\section{SER «ESPOSA DE» EN LA REPRESIÓN FRANQUISTA}

\section{AL PROFESORADO}

En el Madrid de los años treinta, Rosario coincidió con el poeta canario Fernando González Rodríguez en diferentes espacios y ambientes. Puede que coincidieran en la Facultad de Filosofía y Letras de la Universidad Central, pero es más probable que se conocieran en el claustro del Instituto Antonio Nebrija, donde fueron compañeros, o en el Ateneo. ${ }^{24}$ Sea como fuere, Acabaron casándose en 1935 y tuvieron un hijo. La actividad política republicana de su marido es relevante por las consecuencias que tuvo para ambos.

Desde el inicio de la guerra, a partir de 1936, las autoridades franquistas crearon todo un entramado legal para expurgar al personal docente, y poder acabar así con la labor educativa republicana, por el temor a que hubiera personas alejadas de la doctrina nacionalcatólica que pudieran educar en unos valores contrarios al régimen. Las investigaciones sobre

\footnotetext{
funcionaria y aquellas no vinculadas a su empleo de carrera. Constan en el expediente del Archivo Central del Ministerio de Educación (en adelante, ACME) diferentes documentos referidos a esta compatibilidad.

22 Rosario Fuentes, [Instancia pidiendo excedencias tras la toma de posesión en el Instituto San Isidro de Madrid], 30 de septiembre de 1961, caja 97184, ACME.

23 Rosario Fuentes, [Solicitud de excedencia voluntaria de las Escuelas Normales de Madrid], 25 de septiembre de 1967, caja 97184, ACME.

24 En algunos trabajos se atribuye erróneamente a Valladolid el ser la ciudad donde se conocieron. No obstante, es una hipótesis que hay que rechazar, pues Fernando no va por esa ciudad hasta después de la guerra, y hay poemas de amor de 1924 dedicados a una tal «Rosario», aunque, como indica su hijo, puedan no referirse a ella necesariamente (Véase Fernando González, Hogueras en la montaña (Madrid: Imprenta Clásica Española, 1924), 95-99). Rosario era también miembro del Ateneo de Madrid, que frecuentaba también Fernando (Véase Ángeles Ezama, Las musas suben a la tribuna. Visibilidad y autoridad de las mujeres en el Ateneo de Madrid (1882-1939) (Madrid: Genueve Ediciones, 2018), 378).
} 
los procesos de depuración del profesorado de los diferentes niveles educativos en España durante el franquismo arrojan datos de carácter cualitativo y de carácter cuantitativo que permiten tener una visión global del tema: fueron sancionados más del 24\% de maestros/as, el 27,5\% del profesorado de institutos y un poco más del $21 \%$ del profesorado de las Escuelas Normales. ${ }^{25}$ Solo en el Archivo General de la Administración existen más de 2445 expedientes de depuración de profesorado de institutos de segunda enseñanza. ${ }^{26}$ Para todos ellos, independientemente de la resolución, el proceso depurador supuso un antes y un después en sus prácticas pedagógicas y su libertad de expresión.

Fernando González fue víctima de un proceso de depuración cuyo resultado fue una sanción que lo separó del cuerpo de catedráticos entre 1939 y $1955^{27}$ por su actividad política. ${ }^{28}$ Hay que tener en cuenta, cuando se habla de estos procesos de depuración, que no solo se purgó a parte del profesorado por cuestiones ideológicas, sino que todo él estaba bajo sospecha por la mera posibilidad de difundir ideas contrarias al régimen y tenía, por tanto, una función preventiva. ${ }^{29} \mathrm{Si}$ estos procesos suponían en sí mismos actos de injusticia con consecuencias inmensurables, el caso de la depuración de las mujeres era, en muchas ocasiones, todavía más sangrante al no valorar sus propias ideas o actos, sino los de

\footnotetext{
25 Juan Manuel Fernández, «La destrucción de la modernidad republicana. (Sin)razones del exilio pedagógico español», Historia y Memoria de la Educación 9 (2019): 77. https://doi.org/10.5944/ hme.9.2019.22520

26 Francisco Martín, Isabel Grana y Carmen Sanchidrián, «La depuración franquista de los docentes: control y sometimiento ideológico», Historia de la educación 29 (2010).

27 «Órdenes separando definitivamente del servicio a los Catedráticos de Universidades e Instituto que se citan», BOE 230, 18 de agosto de 1939 y [Orden dejando sin efecto la O.M. de 29 de julio de 1939 que le separó del servicio y reintegrándole al mismo con la sanción de traslado fuera de la provincia durante cinco años e inhabilitación para el ejercicio de cargos directivos y de confianza], 30 de diciembre de 1955, caja 97198, ACME.
}

28 Era conocida su actividad republicana desde los tiempos de la dictadura de Primo de Rivera. Estuvo afiliado a Acción Republicana -y formó parte de su Consejo Nacional- y a Izquierda Republicana, presentándose como cabeza de lista por Las Palmas de este último en las elecciones generales de 1936 (Véase $A B C, 10$ de febrero de 1936, p. 17, «Ante las Juntas Provinciales del Censo se proclamaron ayer los candidatos que han de luchar en las elecciones del próximo domingo»).

29 Carmen Sanchidrián, Isabel Grana y Francisco Martín, «Análisis y valoración de los expedientes de depuración del profesorado de Instituto de Segunda Enseñanza en el franquismo (19361942). Resultados generales», Revista de Educación 356 (2011). https://doi.org/10.4438/1988-592XRE-2011-356-044 
sus parejas o familiares varones. ${ }^{30}$ Este fue el caso de la catedrática Rosario Fuentes, cuyo expediente de depuración arroja información clara sobre la incidencia de la depuración en mujeres que no necesariamente tuvieron actividad política conocida. ${ }^{31}$

La Comisión Depuradora C de Valladolid emitió un informe en mayo de 1937 en que se admitía que era «desconocida su ideología política por residir en Madrid», pero se subrayaba que estaba "casada con un izquierdista». También se decía que:

[El director del Instituto Zorrilla] observó [en] Doña Rosario Fuentes buena conducta política y social durante el tiempo que desempeñó su cátedra de Francés, aunque solía cometer algunas faltas de asistencia clase, atraída por Madrid [...] Era de ideas derechistas, pero desde su matrimonio con Don Fernando González, catedrático de Literatura en el Instituto Velázquez de Madrid, y candidato en las últimas elecciones a diputados a Cortes por Las Palmas y afecto al partido de Azaña, parece que simpatizaba con la política de izquierdas.

El expediente quedó en suspenso hasta que las tropas franquistas ocuparan la capital y pudiera conocerse su actitud «al surgir el glorioso Movimiento Nacional». En febrero de 1939, Rosario presentó la preceptiva declaración jurada en la que negaba vinculación con organizaciones políticas o sindicales a la vez que nombraba personas que pudieran confirmarlo (Nicolás de Otto, catedrático de la Universidad de Valladolid y vicecónsul de Venezuela en Barcelona; Catalina Moreno Cortijo, oficial de Secretaría del Instituto Maragall; Isabel Pascual de Pobil, prima suya y esposa del hermano del dictador, Nicolás Franco Bahamonde, embajador de España en Lisboa; y Miguel de Hoyos Juliá, director del Instituto Zorrilla de Valladolid). Junto a esta declaración, Rosario pedía en un escrito adjunto el «reingreso en el escalafón de Catedráticos de Instituto en las mismas condiciones en que se hallaba el día 18 de julio de 1936» tras explicar que fue agregada al Instituto Maragall de Barcelona junto a su marido.

\footnotetext{
30 María Antonia Salvador, «La depuración del profesorado femenino en la guerra civil: el caso de Doña Rosario Fuentes del Instituto Zorrilla de Valladolid», CEE Participación Educativa 15 (2010): 228.

31 Comisión C Valladolid Cultura y Enseñanza, «Expediente de D ${ }^{a}$ Rosario Fuentes Pérez, Catedrático del Instituto Zorrilla, Valladolid», Signatura 32-16752-00020, AGA.
} 
No obstante, la Auditoría de Guerra de Cataluña (dependiente del Juzgado Militar Especial de Depuración de Funcionarios Civiles) resolvió el 16 de septiembre que:

Es atinente reseñar con especialidad los informes oficiales del mismo recibidos por este Juzgado hasta la fecha que en extracto y literalmente le reputan de «casada con Fernando González Rodríguez, persona de muy malos antecedentes según se sabe por el informe dado de dicho señor. Mala funcionaria por su poco celo».

En marzo de 1940, la Comisión le imputó los siguientes cargos y le daba un plazo de ocho días para responder a dichas acusaciones, como hizo el 25 de marzo:

$1^{\circ}$. Haber manifestado simpatía por la política de izquierdas.

Respecto a este cargo, Rosario contestó, en consonancia con todas las declaraciones previas, que no había estado afiliada a ningún partido político ni a ninguna organización sindical de izquierdas y que, aunque «jamás» había hecho «ni por escrito ni de viva voz, manifestación alguna en tal sentido» porque "ni entendía ni le interesaba», su posición había sido siempre «de derechas». Añadía, además, que a ella no le influyó ni directa ni indirectamente que su marido estuviera afiliado a un partido republicano, sino que fue más bien al revés. Finalmente, indicaba que podían corroborar lo expuesto el rector de la Universidad Cayetano de Mergelina, el director del Instituto Zorrilla Miguel de Hoyos, el director de la Escuela de Comercio Adolfo Delibes y los catedráticos de instituto José Martín Alonso y Narciso Alonso Cortés.

$2^{\circ}$. Haber demostrado poco celo en el cumplimiento de su deber profesional.

En este cargo, por el tono y por el contenido, pero además porque lo dice explícitamente, contestaba «profundamente dolorida». Merece la pena reproducir la respuesta literal:

Profundamente dolorida me pongo a contestar a este cargo. Si se entiende por falta de celo el no tener vocación por los estudios propios de mi asignatura, bastarán para rechazar tal imputación los siguientes hechos o datos: fui el número 1 de mis oposiciones, en las que se cubrieron trece cátedras; gané en concurso-oposición 
la plaza de Profesor de Francés de la Universidad de Valladolid; he publicado cuatro tomos de Lengua Francesa; he traducido diversas obras, y actualmente trabajo en otros estudios relacionados con la asignatura de que soy titular en este Instituto. No hablo del concepto que como Profesora de Francés se tiene de mi en esta población, porque seguramente esa Comisión no lo desconoce.

Si por falta de celo se entiende la falta de asistencia a clase, debo manifestar lo siguiente: cuando en vísperas de fiesta he dejado de asistir un día a clase para marchar a Madrid, ha sido con la autorización del Director del Instituto, que estaba facultado para hacerlo bajo su responsabilidad, por las disposiciones vigentes; en esos casos se encargaba de dar las clases la Auxiliar numeraria de Francés, que estaba y está para estos casos. En otras ocasiones me he ausentado de Valladolid los tres últimos días de la semana después de haber dado todas mis clases, ya que el Horario de Clases aprobado por el Claustro del Instituto y refrendado por el Rector de la Universidad, distribuía mis horas de trabajo entre los tres primeros días de cada semana. En uno y en otro caso, y con conocimiento y autorización del Director, marchaba a Madrid, donde tenía enfermos a mi madre y a mi padre, éste General del Ejército Español, con más de noventa años de edad y una historia militar que alcanza desde la guerra de África de 1860 hasta la guerra de Cuba de 1898; y que no contaban con otra hija que yo.

También he dejado de asistir a clase alguna temporada, pero ha sido porque el Ministerio de Instrucción Pública, del que dependía como funcionaria, me concedía pensión para el Extranjero.

Con lo expuesto creo que queda desmentido y aclarado lo referente a mi pretendida simpatía por la política de izquierdas y mi supuesta falta de celo en el cumplimiento de mi deber profesional.

El 16 de octubre de 1940, la Comisión depuradora de Valladolid propuso que fuera confirmada en su cargo, pero «con inhabilitación para desempeñar puestos directivos y de confianza». Finalmente, fue sancionada con ese castigo por una Orden de 16 de diciembre de $1940^{32}$. Tuvo

32 «Órdenes por la que se resuelven expedientes de depuración por las Comisiones depuradoras C) de las provincias que se indican», BOE 18, 18 de enero de 1941. 
que esperar más de doce años a la Orden Ministerial de 24 de diciembre de $1952^{33}$ para que se le cancelara esta doblemente injusta sanción que le fue impuesta, no ya por su pensamiento y actividad política, que no pudieron censurar, sino por la de su marido.

\section{EL PAPEL DE LA JAE EN LA INVESTIGACIÓN CIENTÍFICA Y EDUCATIVA POR PARTE DE «MUJERES EXPLORADORAS»}

La faceta de Rosario Fuentes como investigadora se remonta a los años veinte. En 1927 estableció su residencia de manera temporal en París para realizar estudios filológicos como preparación para la obtención de su cátedra. Como resultado de esta estancia, podemos suponer que tuvo como resultado un estudio comparativo entre el francés y el castellano de una treintena de páginas. ${ }^{34}$

A partir de los años treinta, esta tarea está vinculada a oportunidades para salir al extranjero que le brindaba la Junta para la Ampliación de Estudios e Investigaciones Científicas (JAE). En este sentido, la JAE creó un sistema de becas -en aquella época, se utilizaba el término "pensiones»- para salir del país a ampliar la formación en igualdad de condiciones entre hombres y mujeres. ${ }^{35}$

En agosto de 1930, Rosario Fuentes solicitó a la Junta una pensión para París entre octubre de ese año y junio de 1931 para ampliar sus estudios sobre la lengua y la literatura francesas del siglo XIV para establecer comparaciones con las españolas de la misma época. Finalmente, el 21 de octubre de 1930 se le concedió la pensión solicitada por nueve meses $^{36}$ y fue a realizar su estancia al año siguiente. Durante ese período, pudo acudir al II Congreso Internacional de Profesores de Lenguas Vivas organizado por la Association des Professeurs des Langues Vivantes

\footnotetext{
33 «Orden (rectificada) sobre cancelación de notas relativas a sanciones en los expedientes de depuración o de revisión de los funcionarios del Ministerio de Educación Nacional», BOE 24, 24 de enero de 1953.

34 Rosario Fuentes, «La expresión de las relaciones locales de la lengua francesa. Estudio histórico comparado», marzo de 1928, pp. 3-4, Trabajos, expediente JAE/57-421, Archivo de la JAE.

35 Leoncio López-Ocón, «Al hilo del centenario de la JAE (1907-1939): reflexiones sobre la dinamización de un sistema científico y educativo», Ayer 70 (2008).

36 Junta de Ampliación de Estudios, Memoria correspondiente a los cursos 1928-29 y 1929-30 (Madrid: Junta de Ampliación de Estudios, 1930): 106.
} 
de l'Enseignament Public (APLV) entre el 31 de marzo y el 4 de abril de 1931, al que acudieron 700 congresistas de 25 nacionalidades diferentes, siendo ella la única asistente española. ${ }^{37}$ En este sentido, continuó vinculada a los intentos de organización del profesorado de lenguas vivas, acudiendo como única delegada en 1934 a la reunión del Comité de la Federación Internacional de Profesorado de estas lenguas en París e incluso en una hoja de servicio, que se presentaba frecuentemente para determinados trámites, alega que fue fundadora y primera secretaria de una asociación española de profesorado de lenguas vivas. ${ }^{38}$

En febrero de 1932 la catedrática presentó una nueva solicitud para poder sufragar los gastos de desplazamiento y alojamiento en Alemania durante cuatro meses. El propósito del viaje era estudiar la organización y los problemas de la enseñanza en este país, especialmente en lo referente a lenguas vivas y modernas, para poder conocer las nuevas metodologías activas y sistemas como, por ejemplo, la aplicación de medios auxiliares como el gramófono, introducirlas en sus clases y publicar obras enmarcadas en estas nuevas orientaciones adecuadas a las necesidades de la enseñanza oficial española.

En esa solicitud, planteó dos períodos diferentes. El primero, entre junio y octubre, para poder asistir a los cursos de verano I y VII del Zentralinstitut für Erziehung und Unterricht de Berlín. El primer curso ofrecía en su programa una introducción a la constitución e instituciones educativas alemanas, visitas a escuelas de diferentes modelos y titularidad -tanto estatales como privados-. El otro curso daba una introducción para filólogos extranjeros a los trabajos de la enseñanza superior alemana, una exposición de métodos de los sectores teóricos y prácticos más importantes y visitas a institutos de segunda enseñanza, a la Escuela Superior de Gimnasia y a las escuelas al aire libre. El segundo período planteado era entre diciembre y enero de 1933, para poder acudir a los cursos normales de centros educativos alemanes. A pesar de que finalmente se le otorgó una pensión -de 300 pesetas mensuales y 600 para viajes de ida y vuelta- en julio, para disfrutarla a

\footnotetext{
37 María Martínez de Blanco, «La Federación Internacional de Profesores de Lenguas Vivas», en Nuevos métodos en la enseñanza de idiomas, ed. Luis Grandía (Madrid: Dirección General de Enseñanza Media, 1962), 851.

38 Rosario Fuentes, «Hoja de servicios», 16 de noviembre de 1960, caja 97184, ACME.
} 
partir de octubre, no llegó nunca a hacer uso de ella. Solicitó un aplazamiento porque fue nombrada catedrática interina en el Instituto Antonio Nebrija de Madrid, un centro de nueva creación y que necesitaba la presencia de todo su profesorado para organizar sus inicios. ${ }^{39}$

Las principales peticiones de estudios en el extranjero en la JAE eran de Educación y Pedagogía. ${ }^{40}$ En cualquier caso, que un gran número de mujeres pudiera vivir esta experiencia en las mismas condiciones que los hombres demostraba que las mujeres habían alcanzado los mismos niveles educativos que ellos y que podían desarrollar las mismas actividades viajando solas, sin padres y sin maridos, y teniendo que desenvolverse en otro idioma diferente a su lengua materna.

Rosario también participó en el crucero universitario por los principales destinos culturales de la cuenca del mar Mediterráneo el verano de 1933. Fue una experiencia viajera en la que participaron varias generaciones estudiantiles y profesorado universitario, así como referentes intelectuales de la época, por lo que no solo fue una propuesta educativa fuera de las aulas, sino que funcionó también como embajadora cultural de la República. ${ }^{41}$

En definitiva, Rosario Fuentes y otras compañeras fueron «mujeres exploradoras ${ }^{42}$ que iban más allá del mero viaje, cogiendo trenes lentísimos e incómodos y pasando penurias para indagar y explorar la cultura, el feminismo y la educación que se estaba desarrollando en países como Francia para mejorar la educación en España, un momento de «transferencia cultural» fundamental para entender la historia del pensamiento europeo de aquel tiempo. ${ }^{43}$

\footnotetext{
39 Expediente JAE/57-421, Archivo de la JAE.

40 Irene Mendoza, «Mujeres pensionadas en Francia por la JAE. Algunas especificidades», Comunicación presentada en el Congrés Internacional d'Història La Segona República. Cultures i projectes polítics (Barcelona, Universitat Autònoma de Barcelona, 2016).

41 Francisco Gracia y Josep Maria Fullola, El sueño de una generación: el crucero universitario por el Mediterráneo de 1933 (Barcelona: Universitat de Barcelona, 2006): 392 y Daniel Marías, «En busca de nuestras raíces: el crucero universitario de 1933 por el Mediterráneo», conferencia presentada en la UNED el 3 de octubre de 2017 en el marco de una exposición.

42 Teresa Marín, «Viajeras-exploradoras de cultura», Tabanque: Revista pedagógica 24 (2011).

43 María José Solanas, «Historiadores españoles en el París de Braudel: consideraciones sobre las diferentes experiencias historiográficas», en Actas del VII Congreso de la Asociación de Historia
} 


\section{EL CAMINO ENTRE LOS LIBROS Y LAS AULAS: LA TRADUCCIÓN Y LA CREACIÓN DE MATERIAL DIDÁCTICO}

La década de los años veinte del siglo XX vivió también una época de expansión para las mujeres en la construcción y difusión del conocimiento científico. En este caso, Rosario Fuentes tuvo una fructífera actividad como traductora de obras durante la dictadura de Primo de Rivera y la Segunda República, principalmente del francés y del alemán, mayoritariamente relacionadas con la infancia y la educación para la colección «Ciencia y Educación» de la editorial La Lectura, un proyecto editorial vinculado a la revista sobre artes y ciencias fundada por Francisco López Acebal y dirigida por Clemente de Velasco. ${ }^{44}$

Algunas de estas traducciones tuvieron mucha relevancia en la introducción de obras clave para entender el desarrollo de algunas disciplinas o ámbitos en España. Por ejemplo, gracias a su traducción en 1928, se introdujo en España la obra La Escuela Única de Lacroix, una obra fundamental para entender los fundamentos educativos de diferentes corrientes educativas de la época y que influyó en la filosofía educativa de la Segunda República. ${ }^{45}$ También tradujo del alemán en 1934 el libro El desarrollo espiritual del niño, de Karl Ludwing Bühler, un volumen que contribuyó notablemente a la difusión y consolidación de la psicología evolutiva española en la primera mitad del siglo XX, según la clasificación realizada por José Antonio Gallardo.46

Pero Rosario no solo se dedicó a la traducción, sino que, fundamentalmente a partir de los años cuarenta, también escribió libros sobre la lengua y la literatura francesa y su didáctica, especialmente antologías,

Contemporánea, Memoria e Identidades (Santiago de Compostela: Publicaciones de la Universidad de Santiago de Compostela, 2004).

44 Francisco López Acebal fue un escritor y editor vinculado a la JAE, ocupó el cargo de vicesecretario y fue vocal de la dirección de la Residencia de Estudiantes. Clemente de Velasco fue diputado por el Partido Liberal en las Cortes y fue presidente de la Federación de Sindicatos Agrícolas (Véase Antonio Marco, «Las revistas francesas en "La Lectura" (Madrid, 1901-1920)», en Imágenes de Francia en las letras hispánicas, ed. Francisco Lafarga (Barcelona: Promociones y Publicaciones Universitarias, 1989), 345-354).

45 José María Hernández (ed.), Francia en la educación de la España contemporánea (1808-2008) (Salamanca: Ediciones Universidad de Salamanca, 2011), 88.

46 José Antonio Gallardo, «Selección de libros de texto que influyeron en la difusión y consolidación de la psicología evolutiva española: desde 1901 hasta 1950», Revista de historia de la psicología 39, 3-4 (2008): 64. 
compendios de textos y libros escolares. La autoría femenina de los libros de texto era algo inusual en la época. De manera gráfica, entre 1902 y 1939 únicamente cinco libros de los autorizados y censurados en segunda enseñanza fueron escritos por mujeres. ${ }^{47}$

A falta de un análisis específico de sus libros de texto de francés enmarcado en la investigación de esta didáctica específica, se pueden tener en cuenta las consideraciones que hicieron sobre ellos algunas personalidades relevantes. Así, el filólogo y catedrático Ángel Lacalle o el literato de la generación del 27 y director de la Real Academia Española (RAE) Dámaso Alonso valoraban que estuvieran «muy bien orientados, escritos con sencillez y claridad y con un asombroso sentido común que falta a casi todos los libros de texto ${ }^{48} \mathrm{y}$ "su sentido moderno de la enseñanza y claridad».49 También fue valorada de manera positiva su Antología de la Literatura Francesa por el académico de honor de la RAE José Manuel Blecua, quien llegó a recomendarla a profesores de francés. ${ }^{50}$

Pero ¿eran sus libros utilizados en las aulas a pesar del control exhaustivo por parte de las autoridades franquistas respecto a los textos en escuelas y bibliotecas? ${ }^{51}$ Aunque autores como Lacroix fueron perseguidos y, por tanto, su traducción de La Escuela Única fue retirada por la depuración llevada a cabo en las bibliotecas, ${ }^{52}$ sí hay constancia del uso de sus libros

47 José Luis Villalaín, Manuales escolares en España. Tomo III. Libros de texto autorizados y censurados (1874-1939) (Madrid: UNED, 2002), 510-513.

48 Ángel Lacalle, [Carta a Fernando González Rodríguez], 8 de junio de 1942, archivo epistolar del Fondo Fernando González, Archivo de la Red de Bibliotecas Canarias (en adelante, BiCa).

49 Dámaso Alonso, [Carta a Rosario Fuentes], 30 de octubre de 1942, archivo epistolar del Fondo Fernando González, BiCa.

50 José Manuel Blecua, [Carta a Fernando González], 18 de enero de 1941, archivo epistolar del Fondo Fernando González, BiCa.

51 Sobre la censura y control de libros de texto, véase Gabriela de Lima, «El control del libro durante el Primer Franquismo", Diálogos 18, no. 1 (2014). https://doi.org/10.4025/dialogos.v18i1.850; Antonio Pozo, «Enseñanza de la historia en la escuela española entre 1931-1970. Análisis legislativo-pedagógico y su implantación obligatoria en los libros de texto», CLIO History and History teaching 40 (2014); Juan Antonio Lorenzo, La enseñanza media en la España franquista (1936-1975) (Madrid: Editorial Complutense, 2003). Sobre la depuración de las bibliotecas escolares, véase Ana Martínez Rus, «No sólo hubo censura: la destrucción y depuración de libros en España (1936-1948)», Creneida 5 (2017). https://doi.org/10.21071/ calh.v5i.10368

52 José Andrés de Blas y Carmen Diego, «Un caso paradigmático de represión cultural: depuración de bibliotecas escolares en la provincia de Palencia durante la Guerra Civil española», Represura 7 (2011): Anexo 7. 
de texto tanto por alguna carta ${ }^{53}$ como por la autorización de los organismos franquistas correspondientes. ${ }^{54}$ En sus clases combinaba estos materiales con el uso de otros recursos como el gramófono, normalmente ligado a un carácter activo y oral de la enseñanza y aprendizaje de lenguas extranjeras. ${ }^{55}$

\section{CONCLUSIONES}

Si el acceso de las mujeres a las enseñanzas superiores no se consiguió en igualdad de condiciones hasta el siglo XX, costó más aún su acceso a la enseñanza en dichos niveles. A partir de los años veinte comenzaron a incorporarse mujeres como profesoras de instituto y a ocupar cátedras. Entre estas pioneras, Rosario Fuentes Pérez (1898-1970) consiguió quedar la primera en unas oposiciones vacantes a cátedras de Francés en 1928, en las que varias mujeres ocuparon los primeros puestos. Así, en 1929, se convirtió en la primera mujer catedrática del Instituto Zorrilla de Valladolid.

Esta trayectoria como catedrática se ve complementada por un interés en la investigación sobre cuestiones filológicas, históricas y educativas

53 Ángel Lacalle afirmaba que, a su hija mayor, en el instituto femenino de la capital valenciana, le habían señalado el libro de Rosario como texto (Véase Ángel Lacalle, [Carta a Fernando González Rodríguez], 22 de diciembre de 1941, archivo epistolar del Fondo Fernando González, BiCa).

54 En 1939 se aprobó el uso de Lengua francesa. Primer curso y Lengua francesa. Segundo curso por un curso escolar y un precio de nueve pesetas (Véase «Relación de obras aprobadas definitivamente por la Comisión Dictaminadora de Libros de Texto de Segunda Enseñanza», BOE 315, 11 de noviembre de 1939). En 1940, el uso de la Antología de la Literatura Francesa (Véase «Relación de obras aprobadas por la Comisión Dictaminadora de Libros de Texto para la Segunda Enseñanza», BOE 294, 20 de octubre de 1940), que se volvió a autorizar en 1942 junto al manual escolar Lengua Francesa. Tercer curso e Historia de la Literatura Francesa (Véase «Relación de libros que han sido autorizados para servir de texto en el curso de 1941 al 1942, previo informe del Consejo Nacional de Educación», BOE 53, 22 de febrero de 1942).

55 En ello coinciden diferentes testimonios de antiguos alumnos suyos entrevistados: Arcadio Pardo, Federico Bello y Carlos Malillos. El uso del gramófono estaba relacionado con los métodos eclécticos o mixtos, así como los audiovisuales (Véase Javier Suso, "Método ecléctico o mixto» y "Método audiovisual», ed. Juan F. García Bascuñana, Diccionario de historia de la enseñanza del francés en España (siglos XVI-XX) (Tarragona: Universitat Rovira i Virgili, 2017)). Eran numerosas las ventajas de introducir diferentes medios modernos que pudieran reproducir la voz humana para que el alumnado se familiarizara con el sonido exacto de esa lengua diferente a la suya propia, para poder así imitar los patrones nativos, incorporando la oralidad y el carácter activo propios de un método audio-lingual, aunque ello no siempre tuviera que suponer un cambio en la concepción del aprendizaje y las prácticas hegemónicas (Véase Francisco Luis Hernández, "Los métodos de enseñanza de lenguas y las teorías de aprendizaje», Encuentro: Revista de investigación e innovación en la clase de idiomas 11 (2000)). 
y también contribuyó a la difusión en España de obras especialmente relevantes en el ámbito educativo con diferentes traducciones de obras como La Escuela Única. Como investigadora, tuvo vinculación con las pensiones o becas que ofrecía la Junta para la Ampliación de Estudios (JAE) para realizar trabajos de estudio e investigación en el extranjero. En el caso de Rosario, en 1931 pudo disfrutar de una estancia en París donde tuvo el honor de ser la única española asistente en el II Congreso Internacional de Profesorado de Lenguas Vivas. Más adelante también se le concedió una pensión para ir a Alemania, pero no llegó a disfrutarla por motivos laborales.

Además de la traducción de textos, también los elaboró en el ámbito escolar: libros de texto escolares, antologías poéticas, etc. de los que hay referencias positivas. De hecho, hay constancia de que algunos de ellos fueron autorizados por las comisiones encargadas de aprobar su uso en las aulas y se utilizaron en institutos diferentes al suyo. Así, ella en sus clases -basadas sobre todo en lecturas y traducciones, salpicadas con explicaciones de gramática y, en los últimos cursos, de literatura francesa- combinaba el uso de los libros de su autoría con medios auxiliares como el gramófono, influenciada por corrientes europeas y métodos que fomentaban el carácter oral y activo en el aprendizaje de lenguas vivas. En definitiva, una profesora «de gran humanidad y competencia» que no solo trabajó en Institutos de Segunda Enseñanza (Vigo, Valladolid, Madrid, Badalona y Barcelona), sino que también lo hizo en escuelas de peritos industriales y en Escuelas de Magisterio.

Pero esta relevante trayectoria en múltiples aspectos se vio ensombrecida por el proceso de depuración al que fue sometida por las autoridades franquistas como gran parte del profesorado. En su caso, más sangrante por el hecho de valorar más las cuestiones relativas a su marido que las suyas propias, acusada de «haber manifestado simpatía por la política de izquierdas» y de «haber demostrado poco celo en el cumplimiento de su deber profesional», fue inhabilitada durante doce años para desempeñar cargos directivos y de confianza a pesar de que no se encontrara ningún aspecto que la vinculara a organizaciones de izquierdas, simplemente por «ser mujer de un izquierdista».

En definitiva, Rosario Fuentes Pérez perteneció a una generación de mujeres pioneras en el acceso a la docencia y cátedras en la enseñanza 
media: quedó en primera posición en sus oposiciones a catedrática de francés y fue la primera catedrática del instituto de Valladolid. Aparte de su docencia en diferentes institutos, escuelas técnicas y de formación del magisterio, destacó en campos como la investigación, la traducción y difusión de obras sobre educación, lingüística e historia y la elaboración de recursos didácticos. Un historial manchado por un doblemente injusto proceso de depuración que se saldó con una sanción durante doce años por «ser mujer de».

\section{Nota sobre el autor}

Jorge Fernàndez Gonzàlez es graduado en Magisterio de Educación Primaria por la Universitat de València y Máster de Investigación en Didácticas Específicas con la especialidad de Didáctica de las Ciencias Sociales por la misma institución, donde también ha sido becario de iniciación a la investigación en su Departamento de Didáctica de las Ciencias Experimentales y Sociales. También colabora con el grupo de investigación e innovación en educación geográfica e histórica So$\operatorname{cial}(s) U V$.

Ha coordinado el proyecto audiovisual de recuperación de la historia de los barrios marítimos de la ciudad de València, 46022: memòria de barri y centra sus investigaciones en las representaciones sociales y concepciones epistemológicas sobre las Ciencias Sociales, la historia oral y local, así como el uso de las TIC como recurso didáctico.

Trabaja como maestro en centros públicos del Departament d'Ensenyament de la Generalitat de Catalunya. Durante el curso 2020-2021 ejerce en la Escuela Teresa Miquel i Pàmies de Reus.

\section{REFERENCIAS}

Araque, Natividad. «Las primeras mujeres catedráticas de institutos de enseñanza secundaria en España durante la dictadura de Primo de Rivera y su relación con la JAE». En Aulas modernas, editado por Leoncio López-Ocón, 179-214. Madrid: Universidad Carlos III, 2014.

Benso, Carmen. «Exclusión, discriminación y resistencias: el acceso de la mujer al sistema educativo (1833-1930)». En Xénero e educación social, 
coordinado por Elisa Jato y Lucía Iglesias, 57-78. Santiago de Compostela: Edicións Laiovento, 2003.

Blas, José Andrés de y Carmen Diego. «Un caso paradigmático de represión cultural: depuración de bibliotecas escolares en la provincia de Palencia durante la Guerra Civil española». Represura 7 (2011).

Ezama, Ángeles. Las musas suben a la tribuna: visibilidad y autoridad de las mujeres en el Ateneo de Madrid (1882-1939). Madrid: Genueve Ediciones, 2018.

Fernández, Juan Manuel. «La destrucción de la modernidad republicana. (Sin) razones del exilio pedagógico español». Historia y Memoria de la Educación 9 (2019): 61-99. https://doi.org/10.5944/hme.9.2019.22520

Flecha, Consuelo. Las primeras universitarias en España (1872-1910). Madrid: Narcea, 1996.

Gallardo, José Antonio. «Selección de libros de texto que influyeron en la difusión y consolidación de la psicología evolutiva española: desde 1901 hasta 1950», Revista de historia de la psicología 39, no. 3-4 (2008): 61-67.

González, Fernando. Hogueras en la montaña. Madrid: Imprenta Clásica Española, 1924.

Gracia, Francisco y Josep Maria Fullola: El sueño de una generación: el crucero universitario por el Mediterráneo de 1933. Barcelona: Universitat de Barcelona, 2006.

Hernández, Jose María (ed). Francia en la educación de la España contemporánea (1808-2008). Salamanca: Ediciones Universidad de Salamanca, 2011.

Junta para la Ampliación de Estudios. Memoria correspondiente a los cursos 1928-29 y 1929-30. Madrid: Junta para la Ampliación de Estudios, 1930.

Lima, Gabriela de. «El control del libro durante el Primer Franquismo». Diálogos 18, no. 1 (2014): 361-380. https://dx.doi.org/10.4025/dialogos.v18i1.850

López-Ocón, Leoncio. «Al hilo del centenario de la JAE (1907-1939): reflexiones sobre la dinamización de un sistema científico y educativo». Ayer 70 (2008): 265-278.

Lorenzo, Juan Antonio. La enseñanza media en la España franquista (19361975). Madrid: Editorial Complutense, 2003.

Marco, Antonio. "Las revistas francesas en "La Lectura" (Madrid, 1901-1920)». En Imágenes de Francia en las letras hispánicas, editado por Francisco Lafarga, 345-354. Barcelona: Promociones y Publicaciones Universitarias, 1989.

Marías, Daniel. «En busca de nuestras raíces: el crucero universitario de 1933 por el Mediterráneo». Conferencia presentada en la UNED, 3 de octubre de 2017. Disponible en: https://canal.uned.es/video/5a6f7194b1111f39688b456f

Marín, Teresa, «Viajeras-exploradoras de cultura». Tabanque: Revista pedagógica 24 (2011): 191-206. 
Martín, Francisco, Isabel Grana y Carmen Sanchidrián. «La depuración franquista de los docentes: control y sometimiento ideológico». Historia de la educación 29 (2010): 241-258.

Martínez de Blanco, María. «La Federación Internacional de Profesores de Lenguas Vivas». En Nuevos métodos en la enseñanza de idiomas, editado por Luis Grandía, 849-856. Madrid: Dirección General de Enseñanza Media, 1962.

Martínez Rus, Ana. «No sólo hubo censura: la destrucción y depuración de libros en España (1936-1948)». Creneida 5 (2017): 35-65. https://doi. org/10.21071/calh.v5i.10368

Mendoza, Irene. «Mujeres pensionadas en Francia por la JAE. Algunas especificidades». Comunicación presentada en el Congrés Internacional d'Història La Segona República. Cultures i projectes polítics, Barcelona, 2016.

Pardo, Arcadio. «Los años de Fernando González en Valladolid. La inmersión castellana en su poesía». Estudios Canarios. Anuario del IECan 2, 50-51 (2008): 643-656.

Poveda, María. «Mujeres y segunda enseñanza en Madrid (1931-1939). El personal docente femenino en los institutos de bachillerato». Tesis Doctoral, Universidad Complutense de Madrid, 2014.

Pozo, Antonio. «Enseñanza de la historia en la escuela española entre 19311970. Análisis legislativo-pedagógico y su implantación obligatoria en los libros de texto». Clio. History and History teaching 40 (2014): 28-41.

Salvador, María Antonia. «La depuración del profesorado femenino en la guerra civil: el caso de Doña Rosario Fuentes del Instituto Zorrilla de Valladolid». CEE Participación Educativa 15 (2010): 225-233.

Sanchidrián, Carmen, Isabel Grana y Francisco Martín. «Análisis y valoración de los expedientes de depuración del profesorado de Instituto de Segunda Enseñanza en el franquismo (1936-1942). Resultados generales». Revista de Educación 356 (2011): 377-399. https://doi.org/10.4438/1988-592X-RE-2011-356-044

Sevilla, Diego. "La ley Moyano y el desarrollo de la educación en España». Ethos educativo 40 (2007): 110-124.

Solanas, María José. «Historiadores españoles en el París de Braudel: consideraciones sobre las diferentes experiencias historiográficas». En Actas del VII Congreso de la Asociación de Historia Contemporánea, Memoria e Identidades. Santiago de Compostela: Publicaciones de la Universidad de Santiago de Compostela, 2004.

Suso, Javier. "Método audiovisual». En Diccionario de historia de la enseñanza del francés en España (siglos XVI-XX), editado por Juan F. García Bascuñana [en línea]. Tarragona: Universitat Rovira i Virgili, 2017. Disponible en: http:// www.grelinap.recerca.urv.cat/ca/projectes/diccionario-historia-ensenanza-frances-espana/entradas/150/metodo-audiovisual 
Suso, Javier. «Método ecléctico o mixto». En Diccionario de historia de la enseñanza del francés en España (siglos XVI-XX), editado por Juan F. García Bascuñana [en línea]. Tarragona: Universitat Rovira i Virgili, 2017. Disponible en: http://www.grelinap.recerca.urv.cat/ca/projectes/diccionario-historia-ensenanza-frances-espana/entradas/152/metodo-eclectico-o-mixto

Villalaín, José Luis. Manuales escolares en España. Tomo III. Libros de texto autorizados y censurados (1874-1939). Madrid: UNED, 2002.

Viñao, Antonio. «Del bachillerato de élite a la educación secundaria para todos». En Historia de la Enseñanza Media en Aragón, coordinado por Guillermo Vicente, 449-472. Aragón: Institución Fernando el Católico, 2011. 